\title{
Live birth rate, multiple pregnancy rate, and obstetric outcomes of elective single and double embryo transfers: Hong Kong experience
}

\author{
Joyce Chai *, Tracy WY Yeung, Vivian CY Lee, Raymond HW Li, Estella YL Lau, \\ William SB Yeung, PC Ho, Ernest HY Ng
}

\section{A B S T R A C T}

Objective: To compare the live birth rate, multiple pregnancy rate, and obstetric outcomes of elective single and double embryo transfers.

Design: Case series with internal comparisons.

Setting: University affiliated hospital, Hong Kong.

Participants: Between October 2009 and December 2011, 206 women underwent their first in-vitro fertilisation cycle. Elective single embryo transfer was offered to women who were aged 35 years or below, and had endometrial thickness of $8 \mathrm{~mm}$ or more and at least two embryos of good quality.

Main outcome measures: Live birth rate, multiple birth rate, and obstetric outcomes.

Results: Among the 206 eligible women, 74 underwent an elective single embryo transfer and 132 a double embryo transfer. The live birth rate was comparable in the two groups, being $39.2 \%$ in the elective single embryo transfer group and $43.2 \%$ in the double embryo transfer group, while the multiple pregnancy rate was significantly lower in the elective single embryo transfer group than the double embryo transfer group ( $6.9 \%$ vs $40.4 \% ; \mathrm{P}<0.001)$. Gestational ages and birth weights were comparable in the two groups. There was no significant difference between the two groups with respect to the rate of preterm delivery and antenatal complications $(27.6 \%$ vs $43.9 \%$, respectively; $\mathrm{P}>0.05$ ).

Conclusion: In this selected population, an elective single embryo transfer policy decreases the multiple pregnancy rate without compromising the live birth rate. The non-significant difference in antenatal complications may be related to the small sample size.

Hong Kong Med J 2014;20:102-6

DOI: 10.12809/hkmj134065

J Chai *, FHKAM (Obstetrics and Gynaecology)

TWY Yeung, FHKAM (Obstetrics and Gynaecology)

VCY Lee, FHKAM (Obstetrics and Gynaecology)

RHW Li, FHKAM (Obstetrics and Gynaecology)

EYL Lau, PhD

WSB Yeung, PhD

PC Ho, MD, FHKAM (Obstetrics and Gynaecology)

EHY Ng, MD, FHKAM (Obstetrics and Gynaecology)

Department of Obstetrics and Gynaecology, Queen Mary Hospital, The University of Hong Kong, Pokfulam, Hong Kong

*Corresponding author: jchai@hkucc.hku.hk

New knowledge added by this study

Elective single embryo transfer decreased the multiple pregnancy rate without compromising the live birth rate in women with a good prognosis undergoing in-vitro fertilisation.

Implications for clinical practice or policy

- Elective single embryo transfer should be offered to women with a good prognosis and the care provider should promote this policy through education.

\section{Introduction}

In-vitro fertilisation (IVF) treatment is an effective treatment for various causes of infertility and involves development of multiple follicles after ovarian stimulation, oocyte retrieval, and embryo transfer after fertilisation. Historically, multiple embryos were transferred to compensate for low rates of implantation for individual embryos as well as to achieve higher pregnancy rates. Consequently, IVF carried a high risk of multiple pregnancy and its associated adverse effects on mothers and children. ${ }^{1}$ In 2003 the Chairman of the European Society of Human Reproduction and Embryology (ESHRE) commented that assisted reproduction techniques should result in the birth of one healthy child and that a twin pregnancy should be regarded as a complication. ${ }^{2}$

In January 2013, the "Code of Practice on Reproductive Technology \& Embryo Research" issued by the Council on Human Reproductive Technology of Hong Kong stipulated that no more than three embryos should be placed in a woman in any one cycle. ${ }^{3}$ In August 2001, the Human 
Fertilisation and Embryology Authority in the UK recommended reducing the number of embryos that should be transferred in a single IVF treatment cycle from three to two. ${ }^{4}$

In 2001, ESHRE recommended elective single embryo transfer (eSET) for women aged under 34 years at the time of their first attempt, as soon as they had obtained a top-quality embryo. ${ }^{5}$ In 2008, the British Fertility Society, in conjunction with the Association of Clinical Embryologists, introduced guidelines for eSET in the UK that aimed to reduce IVF multiple pregnancy rates to less than $10 \% .{ }^{6}$ Meta-analyses have shown that in a selected population, compared with double embryo transfer (DET), eSET could reduce multiple pregnancy rates significantly, without compromising cumulative pregnancy rates. ${ }^{7,8}$

Our centre offered eSET to eligible women in order to reduce the multiple pregnancy rate. The aim of this study was to compare the live birth rate, multiple pregnancy rate, and obstetric outcomes after eSET and DET in mothers having their first IVF/ intra-cytoplasmic sperm injection (ICSI) attempt.

\section{Methods}

This was a retrospective study carried out at the Centre of Assisted Reproduction and Embryology, Queen Mary Hospital, The University of Hong Kong, Hong Kong. Clinical details of all treatment cycles were prospectively entered into a computerised database, and checked for correctness and completeness on a regular basis. For this study, data were retrieved for analysis and ethics committee approval was deemed not necessary for retrospective analysis of data.

\section{Patients}

In our programme, a maximum of two embryos were replaced, irrespective of the woman's age. Women were eligible for eSET if they were $\leq 35$ years of age at the time of the embryo transfer, were undergoing their first IVF cycle, had an endometrial thickness of $\geq 8 \mathrm{~mm}$, and had at least two good-quality embryos available for transfer or freezing. Good-quality embryos were defined by their morphological features and cleavage rate, and included embryos with less than $25 \%$ fragmentation and four cells at day 2. Eligible patients were individually counselled about eSET. Women who opted for eSET would have one embryo replaced (eSET group), while those who opted for DET had two embryos transferred (DET group).

\section{Ovarian stimulation and in-vitro fertilisation/intra-cytoplasmic sperm injection procedures}

All women were treated either with the long

\section{選擇性單胚胎移植和雙胚胎移植的活產率、} 多胎率和懷孕結果：香港經驗

柴逸蘭、楊穎兒、李芷茵、李幸奥、劉綺蘭、楊樹標、 何柏松、吳鴻裕

目的：比較選擇性單胚胎移植和雙胚胎移植的活產率、多胎率和懷孕 結果。

設計：具內部對比的病例系列研究。

安排：香港一所大學附屬醫院。

參與者：2009年10月至2011年12月期間，206位婦女首次接受體外受 精。為 35 歲或以下, 並子宮內膜厚度有 8 毫米或以上以及至少有兩個 質量好的肧胎的婦女提供選擇性單肧胎移植。

主要結果測量：活產率、多胎率和懷乃結果。

結果：206名符合條件的婦女中, 74例進行選擇性單胚胎移植, 另 132 例進行雙胚胎移植。兩組的活產率相若, 單胚胎移植組為39.2\%, 雙胚胎移植組為 $43.2 \%$; 而單肧胎移植組的多胎率比雙胚胎移植組明 顯較低（6.9\%比 $40.4 \% ; \mathrm{P}<0.001)$ 。兩組的胎齡和出生體重相若。 兩組之間在早產率及產前併發症方面無顯著差異 $(27.6 \%$ 比 $43.9 \%$; $\mathrm{P}>0.05$ )

結論：在本研究的參與者中, 選擇性單胚胎移植可降低多胎妊娠率而 不影響活產率。產前併發症的非顯著差異可能與研究人數少相關。

gonadotropin-releasing hormone $(\mathrm{GnRH})$ agonist protocol or the $\mathrm{GnRH}$ antagonist protocol for pituitary down-regulation. The details of the long protocol for the ovarian stimulation regimen, handling of gametes, as well as standard insemination and ICSI were as previously described. ${ }^{9}$ In short, women received buserelin (Suprecur; Hoechst, Frankfurt, Germany) nasal spray $150 \mu \mathrm{g} 4$ times a day starting from the mid-luteal phase of the cycle preceding the treatment cycle, followed by human menopausal gonadotropins (hMG) or recombinant follicle-stimulating hormone (FSH) for ovarian stimulation after return of a period. In the $\mathrm{GnRH}$ antagonist protocol, after confirming a basal serum oestradiol level, ovarian stimulation was started with either hMG or recombinant FSH. Ganirelix (NV Organon; Swords Co, Dublin, Ireland) $250 \mu \mathrm{g}$ was started from the sixth day of stimulation. The starting dose of gonadotropin was based on the baseline antral follicle count.

Transvaginal ultrasonography was used to monitor the ovarian response. When the mean diameter of the leading follicle reached $18 \mathrm{~mm}$ and there were at least three follicles reaching a mean diameter of $16 \mathrm{~mm}$ or more, human chorionic gonadotropin (hCG; Pregnyl; Organon, Oss, The Netherlands) 5000 or 10000 units or Ovidrel (Merck Serono, Modugno, Italy) $250 \mu \mathrm{g}$ was given and oocytes were collected about 36 hours later. Fertilisation was carried out in vitro either by 
TABLE I. Demographic and clinical characteristics of the patients referred for sperm cryopreservation $(n=130)^{*}$

\begin{tabular}{|c|c|c|c|}
\hline & eSET $(n=74)$ & DET (n=132) & $P$ value \\
\hline Age of women (years) & $31.8 \pm 2.0$ & $32.7 \pm 2.3$ & $<0.05$ \\
\hline Body mass index (kg/m²) & $21.2 \pm 2.6$ & $21.9 \pm 2.6$ & 0.221 \\
\hline Primary subfertility (\%) & 72.9 & 71.0 & 0.822 \\
\hline Duration of infertility (years) & $4.2 \pm 2.6$ & $3.9 \pm 2.2$ & 0.754 \\
\hline Indication for IVF & & & 0.212 \\
\hline Endometriosis & $7(9.5)$ & $6(4.5)$ & \\
\hline Tuboperitoneal factor & $18(24.3)$ & 25 (18.9) & \\
\hline Male factor & $36(48.6)$ & $61(46.2)$ & \\
\hline Unexplained & $9(12.2)$ & $20(15.2)$ & \\
\hline Mixed factors & $4(5.4)$ & $20(15.2)$ & \\
\hline Basal FSH (IU/L) & $7.6 \pm 1.8$ & $8.0 \pm 3.1$ & 0.971 \\
\hline Baseline antral follicle count & $14.7 \pm 8.1$ & $13.9 \pm 8.3$ & 0.449 \\
\hline Percentage of ICSI (\%) & 35.1 & 34.1 & 0.880 \\
\hline
\end{tabular}

Abbreviations: DET = double embryo transfer; eSET = elective single embryo transfer; $\mathrm{FSH}=$ follicle-stimulating hormone; ICSI = intra-cytoplasmic sperm injection; IVF = invitro fertilisation

* Data are shown as mean \pm standard deviation, \%, or No. (\%)

TABLE 2. Cycle characteristics*

\begin{tabular}{lccc}
\hline & eSET $(\mathbf{n}=\mathbf{7 4})$ & DET $(\mathbf{n}=\mathbf{1 3 2})$ & P value \\
\hline Duration of stimulation (days) & $10.9 \pm 2.5$ & $10.9 \pm 2.0$ & 0.657 \\
Dosage of gonadotropins (IU) & $2048 \pm 920$ & $2139 \pm 779$ & 0.065 \\
Oestradiol level (pmol/L) & $11986 \pm 4966$ & $9545 \pm 4232$ & 0.065 \\
No. of oocytes retrieved & $10.9 \pm 4.3$ & $10.6 \pm 5.7$ & 0.245 \\
No. of embryos at day 2 & $6.7 \pm 3.0$ & $6.1 \pm 3.8$ & 0.060 \\
No. of good-quality embryos & $4.1 \pm 2.0$ & $3.3 \pm 1.7$ & 0.002 \\
\hline
\end{tabular}

Abbreviations: DET = double embryo transfer; eSET = elective single embryo transfer

* Data are shown as mean \pm standard deviation

conventional insemination or ICSI depending on semen parameters. Women were allowed to have replacement of at most two embryos 2 days after oocyte retrieval. A progesterone pessary(Endometrin $100 \mathrm{mg}$ twice per day; Ferring Pharmaceuticals, Parsippany [NJ], US) was administered from the day of embryo transfer for 2 weeks to enable luteal support. Pregnancies were confirmed by positive urine hCG tests and transvaginal ultrasonographic evidence of a gestational sac.

\section{Collection of clinical information}

Clinical information including age, body mass index, basal serum levels of FSH, and baseline antral follicle counts were collected. During IVF treatment, such data included days of stimulation, total dosage of gonadotropin, oestradiol level on day of hCG, number of oocytes retrieved, number of available embryos, number of good-quality embryos, as well as pregnancy and miscarriage rates.

Clinically, pregnancy was defined as the presence of a gestational sac by ultrasonography, whereas the miscarriage rate per clinical pregnancy was defined as the proportion of patients whose pregnancy failed to develop before 20 weeks of gestation. Pregnancy outcome was collected from all pregnant women by a postal questionnaire or by phone. Live birth was defined as the delivery of a fetus with signs of life after 24 completed weeks of gestational age, and the multiple pregnancy rate was calculated as the number of multiple pregnancies divided by the number of clinical pregnancies, expressed as a percentage. Obstetric outcomes including antenatal complications, gestational age at delivery, mode of delivery, and birth weight were also recorded.

\section{Statistical analysis}

The primary outcome measure was the live birth rate and secondary outcomes included the multiple pregnancy rate and obstetric outcomes. Statistical analysis for the comparison of mean values was performed using Mann-Whitney and Student's $t$ tests, as appropriate. The Chi squared and Fisher's exact tests were used to compare categorical variables. Statistical analysis was carried out using the Statistical Package for the Social Sciences (Windows version 20.0; SPSS Inc, Chicago [IL], US). A two-tailed P value of $<0.05$ was considered statistically significant.

\section{Results}

In all, 206 women undergoing their first IVF cycle from October 2009 to December 2011 met the inclusion criteria. A total of 74 women chose eSET and 132 chose DET. Patient and cycle characteristics are shown in Tables 1 and 2, respectively. Women who opted for eSET were significantly younger than those opting for DET, and had a significantly higher proportion of good-quality embryos than those in the DET group.

The IVF and obstetric outcomes are shown in Table 3. Among women with eSET, 40 (54.1\%) had a positive pregnancy test; two were biochemical pregnancies, eight miscarried, and one was an ectopic pregnancy. There was one pair of monozygotic and one pair of dizygotic twins in the eSET group. In women having DET, the positive pregnancy test rate was $58.3 \%(n=77 / 132)$; there were nine biochemical pregnancies, seven miscarriages, and four ectopic pregnancies. In the DET group, the multiple pregnancy rate was $40.4 \%$, which was significantly higher than that in the eSET group $(\mathrm{P}<0.001)$. There were two sets of triplets, of which one underwent fetal reduction to a singleton and the other had fetal reduction to twins. One woman in the eSET group 
and four in the DET group were lost to follow-up for their obstetric outcomes. Overall, the live birth rate was comparable in the eSET and DET groups (39.2\% vs $43.2 \%$, respectively).

The mean gestational age at birth and the median birth weight were not significantly different in the eSET group compared with the DET group $(38.6 \pm 2.2$ vs $37.9 \pm 2.3$ weeks and 2950 [interquartile range, 2830-3157] g vs 2785 [2475-3200] g, respectively). The preterm delivery rate (defined as delivery at $<37$ weeks) and the frequencies of antenatal complications (including gestational diabetes, gestational hypertension, preeclampsia, and placenta praevia) were higher in the DET group, although the difference did not reach statistical significance.

\section{Discussion}

The risk of multiple pregnancy has been a concern in IVF/ICSI as it is associated with adverse maternal and neonatal outcomes. ${ }^{1}$ This is the first study reporting live birth rates and obstetric outcomes after eSET and DET in a selected population in Hong Kong. Our study confirms recent literature findings, ${ }^{7,8}$ by showing that eSET can significantly reduce the multiple pregnancy rate without adversely affecting the live birth rate in young women with good ovarian function. No triplets were observed in the eSET group, but rather unexpectedly it did contain two pairs of twins; one was monozygotic and one dizygotic. Dizygotic twin pregnancy following a single embryo transfer was a rare event, and suggestive of a spontaneous pregnancy occurring concurrently with one due to IVF. ${ }^{10}$ The multiple pregnancy rate of $40.4 \%$ in the DET group and the live birth rates in our study $(39.2 \%$ and $43.2 \%$ in the eSET and DET groups, respectively) were similar to or higher than those previously reported. ${ }^{7,11-14}$

Our study showed that the obstetric outcomes were not significantly different in the two groups. Antenatal complications were more common in the DET group (43.9\% vs $27.6 \%$ in eSET group), although the difference did not reach statistical significance $(\mathrm{P}=0.142)$. Regrettably, data on the Apgar score, neonatal intensive care unit admissions, and perinatal mortality were not available. A recent metaanalysis by Grady et $\mathrm{al}^{15}$ showed that eSET babies were associated with decreased risks of preterm birth and low birth weight than those involving DET. Moreover, eSET singletons had a higher birth weight and lower preterm birth rate than DET singletons, which was postulated to be related to the vanishing twin. ${ }^{16}$ Our study failed to demonstrate the difference but this could be attributed to the small sample size.

Our study was limited by its retrospective nature and small sample size. Also, women having eSET were significantly younger than those having DET, which might lead to possible confounding.
TABLE 3. In-vitro fertilisation and obstetric outcomes*

\begin{tabular}{|c|c|c|c|}
\hline & eSET $(n=74)$ & DET $(n=132)$ & $P$ value \\
\hline Positive pregnancy test rate & $40(54.1)$ & 77 (58.3) & 0.552 \\
\hline Clinical pregnancy rate & $38(51.4)$ & $68(51.5)$ & 0.240 \\
\hline Miscarriage $<20$ weeks & 8/38 (21.1) & 7/68 (10.3) & 0.128 \\
\hline Ectopic pregnancy & $1 / 40(2.5)$ & $4 / 77(5.2)$ & 0.494 \\
\hline Stillbirth & 0 & 0 & 1.000 \\
\hline Live birth rate & $29(39.2)$ & $57(43.2)$ & 0.657 \\
\hline Multiple birth rate & $2 / 29(6.9)$ & $23 / 57(40.4)$ & $<0.001$ \\
\hline Preterm delivery $<37$ weeks & $3 / 29$ (10.3) & $8 / 57(14.0)$ & 0.628 \\
\hline Preterm delivery <32 weeks & $1 / 29(3.4)$ & $3 / 57(5.3)$ & 0.706 \\
\hline Gestation (weeks) & & & 0.102 \\
\hline Mean \pm standard deviation & $38.6 \pm 2.2$ & $37.9 \pm 2.3$ & \\
\hline Median (range) & $38.7(30.1-41.0)$ & $38.2(27.6-41.1)$ & \\
\hline Birth weight (g) & & & 0.202 \\
\hline Mean \pm standard deviation & $2913 \pm 480$ & $2787 \pm 639$ & \\
\hline Median (interquartile range) & $2950(2830-3157)$ & $2785(2475-3200)$ & \\
\hline Antenatal complications & $8 / 29(27.6)$ & $25 / 57$ (43.9) & 0.142 \\
\hline
\end{tabular}

Abbreviations: DET = double embryo transfer; eSET = elective single embryo transfer * Data are shown as No. (\%) or mean \pm standard deviation, unless otherwise stated

The younger mean age in the eSET group could explain the higher number of good-quality embryos available for transfer, which might have an impact on the cumulative pregnancy rate. The cumulative pregnancy rate was not always included as many women still had frozen embryos, but this would be an important aspect to look into in the future. Another bias was that women were allowed to choose between one or two embryos to transfer, instead of allocation by randomisation. Nonetheless, it reflected the actual situation in our centre. Blastocyst transfer is not routinely performed in out unit, because of the possible increased risk of congenital abnormalities and preterm labour, ${ }^{17,18}$ although the pregnancy and live birth rates of the fresh cycle may be higher than those following early cleavage stage transfer. ${ }^{19}$

The eSET policy is increasingly being applied and in a country like Belgium, the law requires eSET for all patients aged under 36 years during their first two IVF attempts. ${ }^{20}$ In Hong Kong, eSET is not imposed and suitable women were given the choice of eSET and DET with detailed counselling. From our data, only a third of the women chose eSET, which suggests that such women are still resistant to eSET. Child et $\mathrm{al}^{21}$ found that $41 \%$ of women having assisted reproductive technology were actually inclined to prefer a twin pregnancy, and some women waiting for IVF treatment viewed severe child disability outcomes more desirable than having no child at all. ${ }^{22}$ This barrier might be overcome by providing 
educational material to women so as to improve their knowledge on outcomes and risks of multiple pregnancies. ${ }^{23}$ The feasibility of eSET also relies on improving outcomes with cryopreserved embryos and the technique on vitrification. Information from the present study may also improve the uptake of eSET in the unit.

Our study confirms that when compared with DET, eSET can reduce the rate of multiple pregnancies without compromising the live birth rate in the fresh cycle. Elective SET should be offered to patients with a good prognosis and IVF centres should promote it, whenever appropriate, through provider and patient education.

\section{Acknowledgements}

The authors would like to thank Mr TM Cheung for data collection.

\section{Declaration}

No conflicts of interest were declared by the authors.

\section{References}

1. Pinborg A. IVF/ICSI twin pregnancies: risks and prevention. Hum Reprod Update 2005;11:575-93.

2. Land JA, Evers JL. Risks and complications in assisted reproduction techniques: report of an ESHRE consensus meeting. Hum Reprod 2003;18:455-7.

3. Council on Human Reproductive Technology, Hong Kong. Code of Practice on Reproductive Technology \& Embryo Research. Available from: http://www.chrt.org.hk/english/ service/service_cod.html. Accessed Apr 2013.

4. HFEA reduces maximum number of embryos transferred in single IVF treatment from three to two [press release]. Human Fertilisation and Embryology Authority; 2001 Aug 8.

5. Prevention of twin pregnancies after IVF/ICSI by single embryo transfer. ESHRE Campus Course Report. Hum Reprod 2001;16:790-800.

6. Cutting R, Morroll D, Roberts SA, Pickering S, Rutherford $\mathrm{A} ; \mathrm{BFS}$ and ACE. Elective single embryo transfer: guidelines for practice British Fertility Society and Association of Clinical Embryologists. Hum Fertil (Camb) 2008;11:13146.

7. McLernon DJ, Harrild $\mathrm{K}$, Bergh $\mathrm{C}$, et al. Clinical effectiveness of elective single versus double embryo transfer: meta-analysis of individual patient data from randomised trials. BMJ 2010;341:c6945.

8. Pandian Z, Bhattacharya S, Ozturk O. Number of embryos for transfer following in vitro fertilization or intracytoplasmic sperm injection. Cochrane Database Syst Rev 2009;(2):CD003416.

9 Ng EH, Yeung WS, Lau EY, So WW, Ho PC. High serum oestradiol levels in fresh IVF cycles do not impair implantation and pregnancy rates in subsequent FET cycles. Hum Reprod 2000;15:250-5.

10. Van der Hoorn ML, Helmerhorst F, Claas F, Scherjon S. Dizygotic twin pregnancy after transfer of one embryo. Fertil Steril 2011;95:805.e1-3.

11. Gremeau AS, Brugnon F, Bouraoui Z, Pekrishvili R, Janny L, Pouly JL. Outcome and feasibility of elective single embryo transfer (eSET) policy for the first and second IVF/ICSI attempts. Eur J Obstet Gynecol Reprod Biol 2012;160:4550 .

12. Fauque P, Jouannet P, Davy C, et al. Cumulative results including obstetrical and neonatal outcome of fresh and frozen-thawed cycles in elective single versus double fresh embryo transfers. Fertil Steril 2010;94:927-35.

13. Thurin A, Hausken J, Hillensjo T, et al. Elective singleembryo transfer versus double-embryo transfer in in vitro fertilization. N Engl J Med 2004;351:2392-402.

14. Council on Human Reproductive Technology, Hong Kong. Reports and statistics. CHRT website: www.chrt.org.hk/ english/publications/publications_rep.html. Accessed Apr 2013.

15. Grady R, Alavi N, Vale R, et al. Elective single embryo transfer and perinatal outcomes: a systematic review and meta-analysis. Fertil Steril 2012;97:324-31.

16. De Sutter P, Delbaere I, Gerris J, et al. Birthweight of singletons after assisted reproduction is higher after single- than after double-embryo transfer. Hum Reprod 2006;21:2633-7.

17. Källén B, Finnström O, Lindam A, Nilsson E, Nygren KG, Olausson PO. Blastocyst versus cleavage stage transfer in in vitro fertilization: differences in neonatal outcome? Fertil Steril 2010;94:1680-3.

18. Dar S, Librach CL, Gunby J, et al. Increased risk of preterm birth in singleton pregnancies after blastocyst versus Day 3 embryo transfer: Canadian ART Register (CARTR) analysis. Hum Reprod 2013;28:924-8.

19. Glujovsky D, Blake D, Farquhar C, Bardach A. Cleavage stage versus blastocyst stag embryo transfer in assisted reproductive technology. Cochrane Database Syst Rev 2012;7:CD002118.

20. Debrock S, Spiessens C, Meuleman C, et al. New Belgian legislation regarding the limitation of transferable embryos in in vitro fertilization cycles does not significantly influence the pregnancy rate but reduces the multiple pregnancy rate in a threefold way in the Leuven University Fertility Center. Fertil Steril 2005;83:1572-4.

21. Child TJ, Henderson AM, Tan SL. The desire for multiple pregnancy in male and female infertility patients. Hum Reprod 2004;19:558-61.

22. Scotland GS, McNamee P, Peddie VL, Bhattacharya S. Safety versus success in elective single embryo transfer: women's preferences for outcomes of in vitro fertilization. BJOG 2007;114:977-83.

23. Hope N, Rombauts L. Can an educational DVD improve the acceptability of elective single embryo transfer? A randomized controlled study. Fertil Steril 2010;94:48995 